\title{
Investigation of Jervol Water Types Properties Effects on Underwater Optical Wireless OCDMA System Performances for Different Modulation Techniques
}

Chahinaz Kandouci ( $\sim$ chahinazkandouci@gmail.com )

telecommunications and digital signal processing laboratory https://orcid.org/0000-0002-2619-2624

\section{Research Article}

Keywords: UWOC, OCDMA, Optical Modulations, Attenuation, Water type

Posted Date: July 19th, 2021

DOl: https://doi.org/10.21203/rs.3.rs-599372/v1

License: (c) (i) This work is licensed under a Creative Commons Attribution 4.0 International License. Read Full License

Version of Record: A version of this preprint was published at Optical and Quantum Electronics on November 24th, 2021. See the published version at https://doi.org/10.1007/s11082-021-03390-0. 


\title{
Investigation of Jervol Water types properties effects on Underwater Optical Wireless OCDMA System Performances for Different Modulation Techniques
}

\author{
Chahinaz Kandouci
}

Received: date / Accepted: date

\begin{abstract}
In this paper, an analytical evaluation of direct detection OCDMA system using zero cross correlation codes is presented in an underwater wireless optical channel (UWOC). Performances were evaluated by varying the main simulation parameters (range,transmitted power,number of users and inclination angle) considering different modulation techniques for different water types (categorized according to Jerlov classification).
\end{abstract}

Keywords UWOC · OCDMA · Optical Modulations · Attenuation · Water type

\section{Introduction}

Underwater wireless optical communications (UWOC) has become the focus subject of many recent wireless communications studies Kaushal and Kaddoum (2016). Allowing high data rates it represents the ideal candidate for underwater transmissions (compared to few kbits/s rates achievable by acoustic and radio-frequency (RF) underwater communicationsChen et al. (2019); Khalighiet al. (2014); Saeed et al. (2019).

In optical oceanography, Jerlov categorized waters into oceanic and coastal types based on it's chlorophyll concentration Solonenko and Mobley (2015) . The latter directly affecting the water's particles sizes and consequently the scattering and absorption effects on any light beam propagation underwater. The objective of this study is, considering these drawbacks, to translate the benefits of Optical Code Division Multiple Acces (OCDMA, more traditionally implemented in optical fibers systems) in UWOC systems.

This paper is organized as follows : In section 2, the UWOC/OCDMA studied

C.Kandouci

Telecommunications and Digital Signal Processing Laboratory, Djillali Liabes University of Sidi Bel Abbes, 22000, Algeria.

E-mail: chahinazkandouci@gmail.com 
system is presented, followed by the channel properties in section 3 . Section 4 is devoted to the Bit error rate calculations considering different modulations schemes. The results issued from these calculations are finally presented and discussed in section 5 .

\section{System description}

The studied system is represented in Fig. 1. On the transmission side each user's spectral signature (defined by it's respective ZCC code sequence) is the modulated the user's data (the different modulation techniques considered in this study are detailed later in this paper,see section 4). It's then diffused thru the water channel by optical lenses. The water inherent properties and particles will strongly affect the signal power. At the receiver, direct detection (DD) technique is used. Introduced by Abdullah et al. (2008), it consists of the detection of only one of the spectral signature's wavelengths (due to the fact that there is no overlap between the ZCC codes users). It allows a simpler system (compared to optical balanced detection conventionally used) , and the low value of captured power at the receiver (do to the fact that only wavelength is detected) will allow us to test the system limitations for the most critical case ( the captured power is $\omega$ times smaller than the one studied in Al Hammadi and Islam (2020) and Yadav and Kumar (2020) , $\omega$ being the code weight).

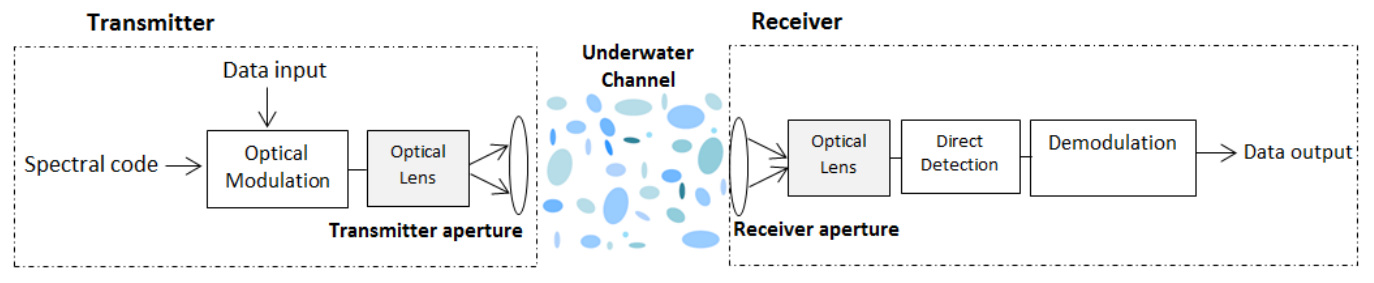

Fig. 1 Schematic diagram of OCDMA UWOC system

\section{UWOC channel properties}

Line of sight (LOS), link configuration, defines the path of communication between transmitter $\left(T_{x}\right)$ and receiver $\left(R_{x}\right)$, as shown in Fig. 2 .In this scenario, $\left(T_{x}\right)$ directs the light beam in the direction of $\left(R_{x}\right)$, where the captured power (in the case of a LOS link of distance $d$ ) $P_{R x}$ is defined as Ghassemlooy et al. (2019):

$$
P_{R x}=P_{T x} \eta_{T x} \eta_{R x} \frac{A_{R x e f f} \cos (\varphi)}{2 \pi d^{2}\left[1-\cos \left(\varphi_{0}\right)\right]} \exp \left[-c(\lambda) \frac{d}{\cos (\varphi)}\right]
$$


Table 1 Absorption, scattering and extinction coefficients for different water types (according to Jerlov classification)

\begin{tabular}{cccc}
\hline Jerlov water type & $a\left(m^{-} 1\right)$ & $b\left(m^{-1}\right)$ & $c\left(m^{-1}\right)$ \\
\hline Clear water & 0.053 & 0.003 & 0.056 \\
Clear ocean & 0.069 & 0.08 & 0.15 \\
Coastal ocean & 0.088 & 0.216 & 0.305 \\
Turbid harbor & 0.295 & 1.875 & 2.17 \\
\hline
\end{tabular}

Where: $P_{T x}$ is the transmitted power, $\eta_{T x}$ and $\eta_{R x}$ are respectively the optical efficiency of the transmitter and the receiver and $A_{R x e f f}$ is the effective aperture area of the receiver.

The captured power also depends on the transmission beam divergence angle $\varphi_{0}$ and the transmitter inclination angle $\varphi$. Those angles are illustrated in Fig. 2 for a LOS link configuration.

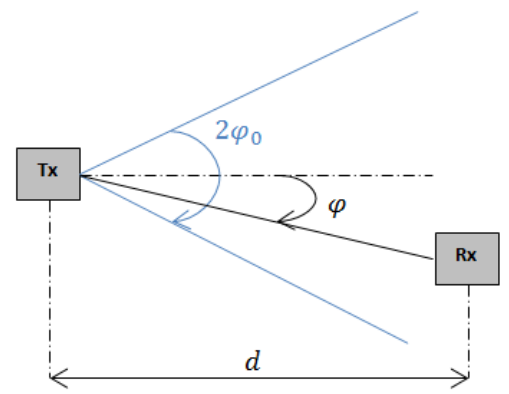

Fig. 2 Beam divergence angle $\left(\varphi_{0}\right)$ and transmitter inclination angle $(\varphi)$ in LOS link

Another important parameter to take into consideration is the attenuation coefficient $c(\lambda)$. In UWOC it depends on the operating transmission wavelength. It's also defined as sum of absorption and scattering coefficient respectively represented by $a(\lambda)$ and $b(\lambda)$ Rashed and Sharshar (2013) :

$$
c(\lambda)=a(\lambda)+b(\lambda)
$$

$a(\lambda)$ and $b(\lambda)$ depend on the concentration of suspended and dissolved particles in the water Rashed and Sharshar (2013), both of which directly affect the light beam propagation. By referring to Jerlov water classification, the typical values of absorption, scattering and extinction coefficients for different water types are listed in table 1: 


\section{BER calculation}

The Signal to Noise Ration (SNR) is defined, depending on the average signal power $i_{k}$ and average power of all noise sources $\sigma$, as :

$$
S N R=\frac{i_{k}^{2}}{\sigma^{2}}
$$

The total variance of noise sources $\sigma^{2}$ is defined as the sum of shot noise variance $\left(\sigma_{s h}{ }^{2}\right)$ and thermal noise variance $\left(\sigma_{t h}^{2}\right)$. In the studied case, the phase induced intensity noise (PIIN) is neglected to the ZCC codes properties (no spectral signatures overlapping between all active users). Hence, considering DD receiver, $i_{k}$ and $\sigma$ can be expressed as (demonstration detailed in Garadi et al. (2017)):

$$
\mathrm{i}_{\mathrm{k}}=\Re . \mathrm{P}_{\mathrm{sr}} \frac{1}{\mathrm{~L}}
$$

and

$$
\sigma^{2}=2 . e \cdot B \cdot i_{k}+\frac{4 k_{b} T_{n} B}{R_{1}}=2 . e . B . \Re . P_{s r} \frac{1}{L}+\frac{4 k_{b} T_{n} B}{R_{1}}
$$

Where $\Re$ is is the photo-detectors responsivity, $B$ is the electrical bandwidth of the receiver, $T_{n}$ is the receiver noise temperature, $K_{b}$ is Boltzmann constant and $R_{1}$ Receiver load resistor Imtiaz et al. (2020), Garadi et al. (2017),Kandouci et al. (2017)

The captured power at the receiver $P_{s r}$, in the case of UWOC channel, is equivalent to $P_{R x}$. Including thus, all the constraints of the underwater channel. From equations $(1),(3),(4)$ and (5), the SNR of the studied system becomes:

$$
\mathrm{SNR}=\frac{\left(\Re \cdot P_{T x} \eta_{T x} \eta_{R x} \frac{A_{R x e f f} \cos (\varphi)}{2 \pi d^{2}\left[1-\cos \left(\varphi_{0}\right)\right]} \exp \left[-c(\lambda) \frac{d}{\cos (\varphi)}\right] \cdot \frac{1}{\mathrm{~L}}\right)^{2}}{\text { 2.e.B. } \Re \cdot P_{T x} \eta_{T x} \eta_{R x} \frac{A_{R x e f f} \cos (\varphi)}{2 \pi d^{2}\left[1-\cos \left(\varphi_{0}\right)\right]} \exp \left[-c(\lambda) \frac{d}{\cos (\varphi)}\right] \cdot \frac{1}{\mathrm{~L}}+\frac{4 \mathrm{~K}_{\mathrm{b}} \mathrm{T}_{\mathrm{n}} \mathrm{B}}{\mathrm{R}_{1}}}
$$

In order to investigate the OCDMA-UWOC studied system performances, it is necessary to evaluate the Bit Error Rate (BER). The relationship between the latter and the SNR depends closely on the modulation scheme chosen Akter et al. (2020). Various modulation techniques , are used in communications systems due their bandwidth efficiency, ease of implementation, and costeffectiveness. The ones considered in this study are : non-return to zero on-off keying (NRZ-OOK), return to zero on-off keying (RZ-OOK) and Quadrature amplitude modulation (QAM).

BER can be expressed, by estimation from SNR, for different modulation schemes as follows Ali (2020) :

- for RZ-OOK Ali et al. (2020):

$$
B E R_{R Z-O O K}=\frac{1}{2} \operatorname{erfc}\left[\frac{1}{2} \sqrt{S N R}\right]
$$


- for NRZ-OOK Zou Wei et al. (2001)

$$
B E R_{N R Z-O O K}=\frac{1}{2} \operatorname{erfc}\left[\frac{1}{2 \sqrt{2}} \sqrt{S N R}\right]
$$

- for M-QAM Mesleh et al. (2011):

$$
B E R_{M-Q A M}=\frac{\sqrt{m}-1}{\sqrt{m} \log _{2} \sqrt{m}} \operatorname{erfc}\left[\sqrt{\frac{3 S N R}{2(m-1)}}\right]
$$

Where $M$ represents the level of the QAM.

\section{Results and discussion}

In this section, BER investigation of DD-OCDMA UWOC is presented for various modulation schemes (cited in section 4). The considered parameters are displayed in table 2 , considering a constant depth and no water turbulence.

Table 2 BER calculation parameters

\begin{tabular}{cc}
\hline Operating parameter & Value \\
\hline Operating wavelength & $575 \mathrm{~nm}$ \\
Transmitter efficiency $\eta_{T x}$ & 0.8 \\
Receiver efficiency $\eta_{R x}$ & 0.8 \\
Data bit rate & $1 \mathrm{Gbit} / \mathrm{s}$ \\
Responsivity $(R e)$ & $0.6(\mathrm{~A} / \mathrm{W})$ \\
Boltzmann constant $\left(k_{b}\right)$ & $1.38 \times 10^{23}(J K)$ \\
Temperature $\left(T_{n}\right)$ & $298(\mathrm{~K})$ \\
Load resistance $\left(R_{l}\right)$ & $1 \mathrm{~K} \Omega$ \\
Transmission distance $(d)$ & $10 \mathrm{~m}$ \\
Transmitted power & $500 \mathrm{~mW}$ \\
Effective aperture area of the receiver & $0.01 \mathrm{~m}{ }^{2}$ \\
Beam divergence angle $\left(\varphi_{0}\right)$ & $60^{\circ}$ \\
Transmitter inclination angle $(\varphi)$ & $5^{\circ}$ \\
\hline
\end{tabular}

Fig. 3 illustrates the bit error rate variation in function of the of number of active users considering a transmission power of $500 \mathrm{~mW}$ and a code weight $\omega=3$ for a $5 m$ transmission distance (in clear water). It shows that the suitable $10^{-} 9$ BER is achievable for 12 active users using NRZ-OOK modulation , around 15 active users using RZ-OOK and 64-QAM modulation and up to 22 users using 16-QAM, making it the more suitable modulation format for the studied scheme.

In fig. 4, the same previous parameters are considered for different water types. In the case of a clear ocean, the suitable BER in only reachable for less than 10 users, and non achievable for a coastal ocean (due to the low value of the transmission power). Turbid water was not discussed in this study do it's 


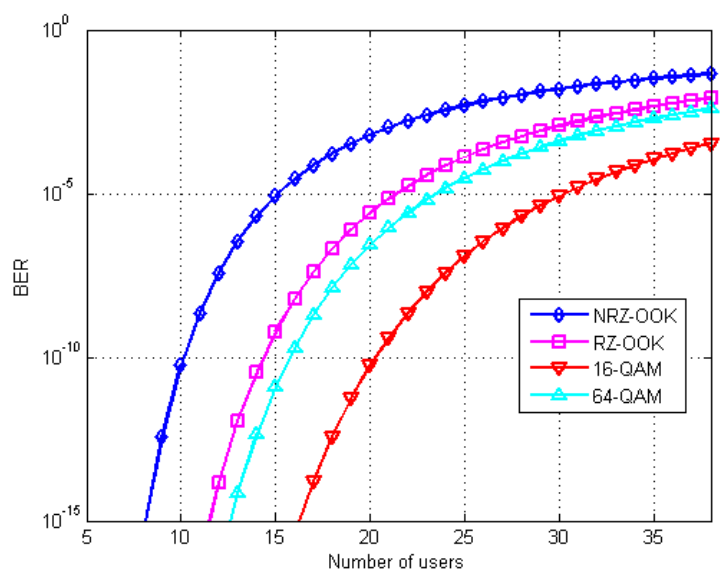

Fig. 3 BER versus number of users for clear water

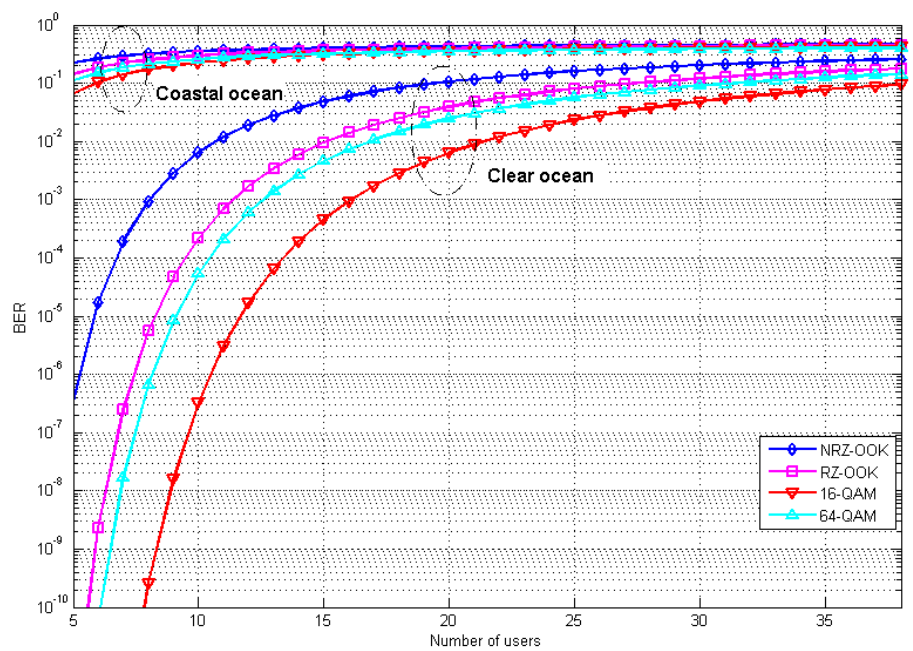

Fig. 4 BER versus number of users for clear and coastal ocean

high attenuation factor (as show in table 1 ).

It is demonstrated in Fig. 5 that the system performance and the increase in transmitted power have a direct positive correlation (which is translated by a decrease in the BER value). Indeed , according to the water type and the spread of it's impurities, more power could be needed to overcome the optical attenuation induced my the channel.

We also studied the range effect by varying the transmission distance for different water types when the number of simultaneous users is 5 and transmitted power is $500 \mathrm{~mW}$ (see Fig 6. As in the previous cases, the BER depends 


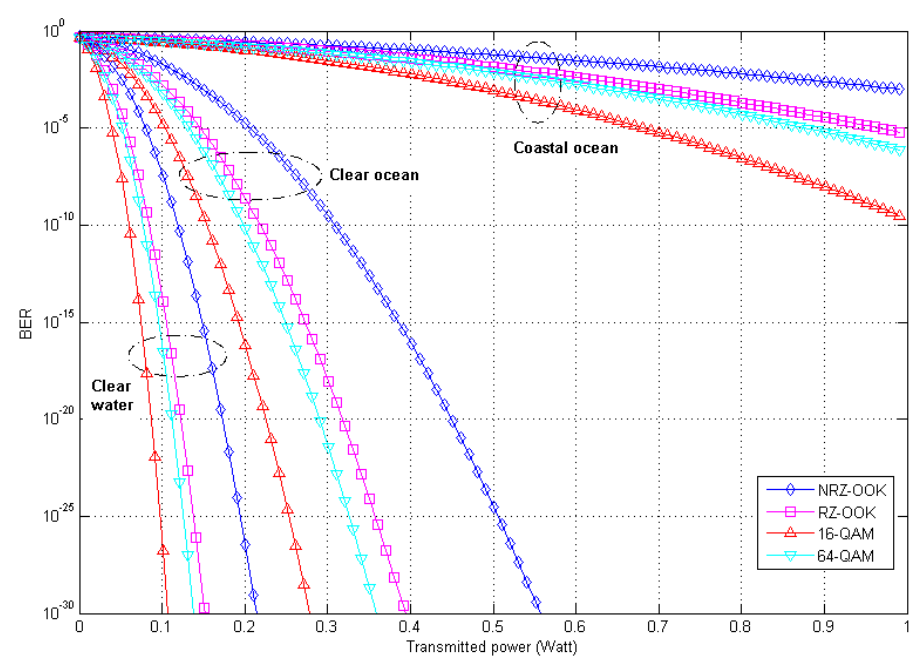

Fig. 5 BER versus transmitted power

strongly on the chosen water type. The maximum ranges with acceptable BER can be reached in for clear water $(26 m)$. 16-QAM also proved to be the more efficient modulation scheme. For other water types, the acceptable system performance can only be achievable for a range not exceeding $10 \mathrm{~m}$ in coastal ocean and $15 \mathrm{~m}$ for clear ocean.

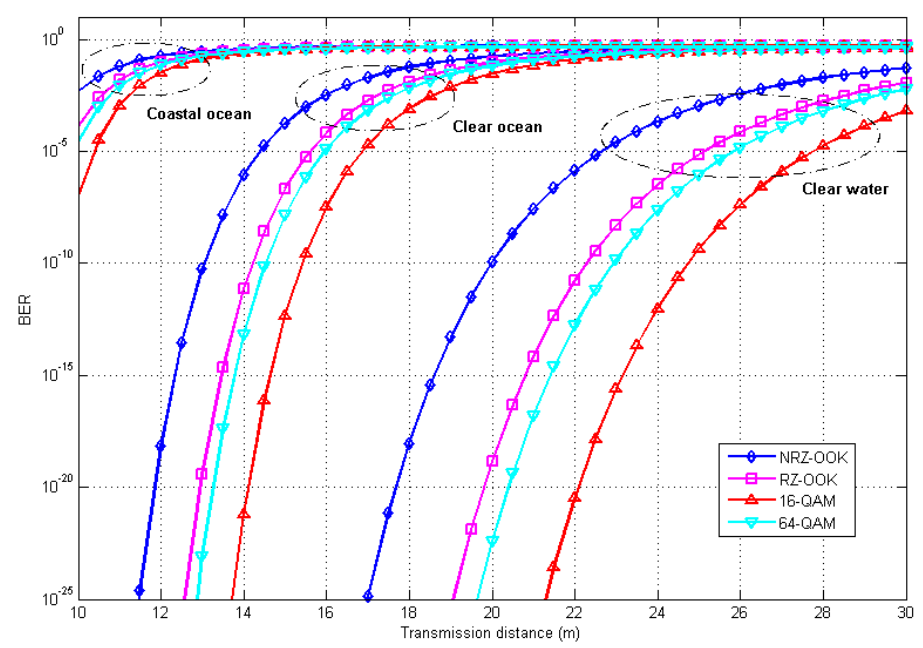

Fig. 6 BER versus transmission distance 
In Fig. 7, the transmitter inclination angle $(\varphi)$ is varying from $0^{\circ}$ to $90^{\circ}$ , for a $60^{\circ}$ beam divergence angle $\left(\varphi_{0}\right) \cdot \varphi$, as shown previously Fig. 2, is defined by an angular value characterizing the deviation between the axis connecting the transmitter-receiver and the source's optical beam trajectory. Therefore, as reflected in Fig. 7, the system performances declines the source beam aligns away from the axis connecting the transmitter and the receiver.

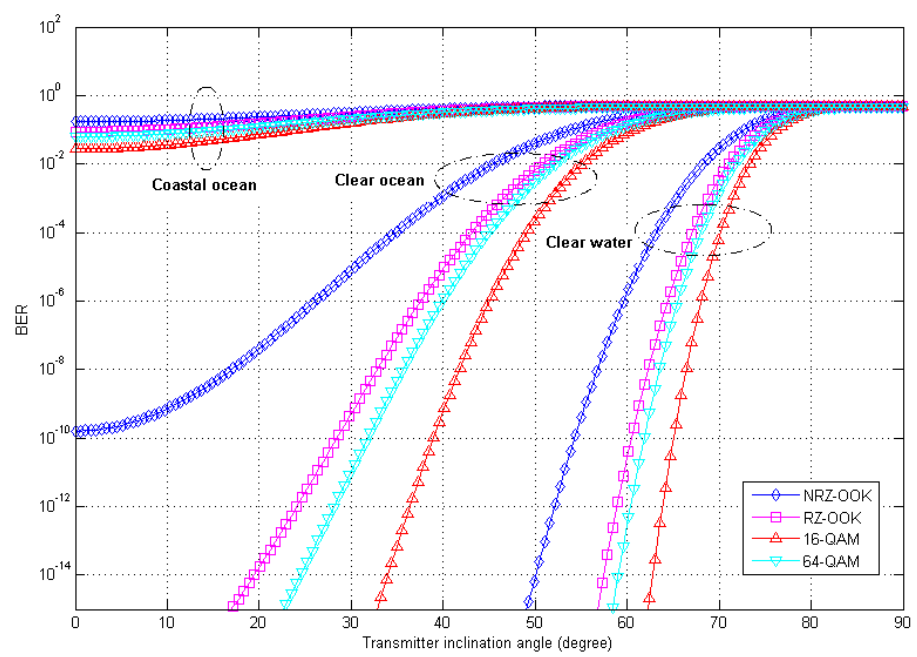

Fig. 7 BER versus transmitter inclination angle

The obtained results are in agreement with existing OCDMA-UWOC works in the literature Al Hammadi and Islam (2020) Yadav and Kumar (2020) with a simpler detection scheme and a significantly smaller captured power at the receiver. This is due to the ZCC codes properties. 16-QAM modulation was also determined to be the most effective in this study case.

\section{Conclusion}

In this paper, the UWOC-OCDMA system performances limitations were evaluated by referring to the bit error rate. In order to optimize the results , 4 different modulations techniques were considered (RZ-OOK , NRZ-OOK , 16QAM and 64-QAM). The constraints considered in this study were the optical attenuation due to water particles and the detection of the lower acceptable power to reconstitute each user's data. Acceptable BER was achievable for a highest link distance of $26 \mathrm{~m}$. 
Ethics approval and consent to participate

Not applicable

\section{Consent for publication}

Not applicable

\section{Availability of data and materials}

Not applicable

\section{Competing interests}

Not applicable

\section{Funding}

Not applicable

\section{Authors' contributions}

Not applicable

Acknowledgements This work was supported by Directorate General for Scientific Research and Technological development (DGRSDT).

\section{References}

Abdullah MK, Hasoon FN, Aljunid S, Shaari S (2008) Performance of ocdma systems with new spectral direct detection (sdd) technique using enhanced double weight (edw) code. Optics Communications 281(18):4658 4662, DOI https://doi.org/10.1016/j.optcom.2008.06.029, URL https://www.sciencedirect.com/science/article/pii/S0030401808005725

Akter M, Islam MJ, Al Hammadi MM (2020) Performance evaluation of various modulation techniques for underwater wireless optical communication system. In: Innovations in Electronics and Communication Engineering, Springer, pp 95-101

Al Hammadi MM, Islam MJ (2020) Performance evaluation of underwater wireless optical cdma system for different water types. Photonic Network Communications 39(3):246-254 
Ali MAA (2020) Investigation of multiple input-single output technique for wireless optical communication system under coastal water. Optical and Quantum Electronics 52(9):416, DOI 10.1007/s11082-020-02534-y, URL https://doi.org/10.1007/s11082-020-02534-y

Ali MAA, Baqi ZH, Rahi SK (2020) On the performance of free space optical communication link over dust environment. AIP Conference Proceedings 2213(1):020105, DOI 10.1063/5.0000241, URL https://aip.scitation.org/doi/abs/10.1063/5.0000241, https://aip.scitation.org/doi/pdf/10.1063/5.0000241

Chen D, Wang J, Li S, Zhengyuan X (2019) Effects of air bubbles on underwater optical wireless communication. Chin Opt Lett 17

Garadi A, Djebbari A, Abdelmalik TA (2017) Exact analysis of signal-to-noise ratio for sac-ocdma system with direct detection. Optik 145:89-94, DOI https://doi.org/10.1016/j.ijleo.2017.07.038, URL https://www.sciencedirect.com/science/article/pii/S0030402617308550

Ghassemlooy Z, Popoola W, Rajbhandari S (2019) Optical Wireless Communications: System and Channel Modelling with Matlab. CRC Press, Boca Raton

Imtiaz WA, Ahmed HY, Zeghid M, Sharief Y (2020) An optimized architecture to reduce the impact of fiber strands in spectral/spatial optical code division multiple access passive optical networks (ocdma-pon). Optical Fiber Technology 54:102072, DOI https://doi.org/10.1016/j.yofte.2019.102072, URL https://www.sciencedirect.com/science/article/pii/S1068520019304110

Kandouci C, Djebbari A, Taleb-Ahmed A (2017) A new family of 2d-wavelength-time codes for ocdma system with direct detection. Optik 135:8-15, DOI https://doi.org/10.1016/j.ijleo.2017.01.065, URL https://www.sciencedirect.com/science/article/pii/S0030402617300864

Kaushal H, Kaddoum G (2016) Underwater optical wireless communication. IEEE Access 4:1518-1547, DOI 10.1109/ACCESS.2016.2552538

Khalighiet al M (2014) Underwater wireless optical communication; recent advances and remaining challenges. In: 2014 16th International Conference on Transparent Optical Networks (ICTON), pp 1-4, DOI 10.1109/ICTON.2014.6876673

Mesleh R, Elgala H, Haas H (2011) On the performance of different ofdm based optical wireless communication systems. IEEE/OSA J Opt Commun Netw 3

Rashed ANZ, Sharshar HA (2013) Performance evaluation of short range underwater optical wireless communications for different ocean water types. Wireless Personal Communications 72(1):693-708

Saeed N, Celik A, Al-Naffouri TY, Alouini MS (2019) Underwater optical wireless communications, networking, and localization: A survey. Ad Hoc Networks 94:101935, DOI https://doi.org/10.1016/j.adhoc.2019.101935, URL https://www.sciencedirect.com/science/article/pii/S1570870518309776

Solonenko MG, Mobley CD (2015) Inherent optical properties of jerlov water types. Appl Opt 54(17):5392-5401, DOI 10.1364/AO.54.005392, URL http://ao.osa.org/abstract.cfm?URI=ao-54-17-5392 
Yadav A, Kumar A (2020) Performance analysis of underwater 2d ocdma system. In: Optical and Wireless Technologies, Springer, pp 477-484

Zou Wei, Shalaby HMH, Ghafouri-Shiraz H (2001) Modified quadratic congruence codes for fiber bragg-grating-based spectral-amplitude-coding optical cdma systems. Journal of Lightwave Technology 19(9):1274-1281, DOI $10.1109 / 50.948274$ 